\title{
FLASH CO-PYROLYSIS OF BIOMASS WITH BIOPOL YMERS: A PRELIMINARY EVALUATION
}

\author{
T. Cornelissen ${ }^{I}$ \\ M. Jans ${ }^{2}$ \\ J. Yperman ${ }^{1}$ \\ G. Reggers ${ }^{I}$ \\ S. Schreurs ${ }^{2}$ \\ T. Thewys ${ }^{I}$ \\ R. Carleer ${ }^{I}$ \\ ${ }^{\prime}$ Hasselt University, Belgium \\ ${ }^{2} \mathrm{NuTeC}$, department IWT, Belgium
}

\begin{abstract}
The influence of biopolymers on the pyrolysis yields is investigated using a semi-continuous home-built pyrolysis reactor. All biopolymers show their specific benefits during the overall co-pyrolysis process. In a first attempt, each pyrolysis (pure willow and all 1:1 w/w ratio willow/biopolymer blends) is evaluated based on nine objectives. Afterwards, Thomas Saaty's Analytic Hierarchy Process is used in order to obtain an objective ranking of the different biopolymer options. The flash co-pyrolysis of $1: 1$ willow/PHB (Polyhydroxybutyrate) is the most performant option, while 1:1 willow/PLA (Polylactic acid), 1:1 willow/Biopearls and 1:1 willow/Potato starch show increased potential as well. The fact that biopolymers, despite their biodegradability, are considered as waste makes the flash copyrolysis of willow and biopolymers an additional necessity.
\end{abstract}

\section{KEYWORDS}

Flash co-pyrolysis; Willow; Biopolymer; Pyrolytic water; Bio-oil; Upgrading; Waste; Synergy; Analytic hierarchy process.

\section{INTRODUCTION}

Since the oil crisis (1970's) and more recently the Kyoto Protocol (2002), the European Union has become aware of the hazardous impact of its dependence on foreign energy sources [1], and started investing in the development of an alternative energy strategy to reinforce its independence. Additionally, materials in general should evolve to become sustainable too (Club of Rome - 1972).

One technology that shows potential to satisfy the demand for both renewable energy and materials is pyrolysis. Pyrolysis is a thermal degradation process in which biomass is heated in an oxygen-free environment and converted to (bio-)char, (bio-)gas and bio-oil, which are all energy carriers [2-4]. Bio-oil can substitute fuel oil or diesel in many static applications. Additionally, it can be upgraded to transportation fuels [5]. Bio-oil does not only offer 
energetic valorisation, it is also a source of value-added chemicals [6, 7]. However, bio-oil often contains up to 300 different compounds [8], making it (at the moment) cumbersome and economically unattractive to isolate chemicals from. Additionally, one of the major drawbacks of bio-oil is that it often has high water content due to the inherent production of pyrolytic water during flash pyrolysis.

Biopolymers, which are a special kind of plastic, originate from renewables and/or are biologically degradable. Despite their biodegradability, most biopolymers still have to be considered as waste, since it would be ecologically unacceptable to dispose of them in the environment. The thermal decomposition of polylactic acid (PLA) and polyhydroxybutyrate (PHB) has already been studied in detail [9-13]. The flash co-pyrolysis of willow and PLA at $4508 \mathrm{C}$ has been reported too and showed a clear synergetic effect, resulting in an increased bio-oil yield with lower water content and a higher calorific value. The synergetic effect was observed to increase along with the addition of PLA [14].

So, the flash co-pyrolysis of biomass and biopolymers seems to be a promising route, not only as a supplier of renewable energy, but also as a supplier of value-added materials, as an attractive method to upgrade bio-oil, and as an alternative waste treatment option. Therefore, a myriad of biopolymers (PLA, Corn Starch, PHB, Biopearls, Eastar, Solanyl and Potato Starch) has been investigated in identical circumstances to evaluate the effect of these different biopolymers on the flash co-pyrolysis behaviour of willow with the aid of Thomas Saaty's Analytic Hierarchy Process [15].

\section{EXPERIMENTAL}

\subsection{Materials}

The experiments are performed on willow, and willow/biopolymer blends with a w/w-ratio of 1:1. Seven different biopolymers are used in this research: polylactic acid (PLA), Corn starch, polyhydroxybutyrate (PHB), Biopearls, Eastar, Solanyl and Potato starch.

As a first step, the experiments on willow/biopolymer blends with a w/w ratio of $1: 1$ are investigated and compared with the results obtained for $100 \%$ pure willow (= reference sample) to evaluate the effects on the flash co-pyrolysis behaviour.

\subsection{Flash pyrolysis}

Flash pyrolysis experiments are executed using a semi-continuous home-built pyrolysis reactor. The entire system is continuously flushed with nitrogen gas to guarantee an "oxygenfree" environment. Within the reactor, a heat transfer medium (white sand) is kept in constant motion with the aid of an Archimedical screw. As soon as the sand inside the reactor reaches the pyrolysis temperature ( $\mathrm{PT}=450 \mathrm{eC}$ ), the nitrogen flow is stopped and an injection system is started; inserting the willow or willow/biopolymer blend into the reactor. The willow or willow/biopolymer blend subsequently undergoes a flash pyrolysis and is converted into volatiles which mainly condense into a recuperation system as condensables (e.g. bio-oil and/or, exceptionally in this research, crystals). The non-condensable gases exit the recuperation system via a chimney into a fume hood. For a detailed description of the experimental flash pyrolysis set-up and procedure, please refer to [14].

\subsection{Analysis}

\subsubsection{Ultimate analysis}


The CHNS- and O-content of the input materials (approximately $2-4 \mathrm{mg}$ of sample) are determined via two distinct experiments, using a FlashEA 1112 Elemental Analyser of Thermo Electron Corporation.

\subsubsection{Thermogravimetric analysis - TGA}

About $30 \mathrm{mg}$ of sample is pyrolysed under approximately $35 \mathrm{~mL} / \mathrm{min} \mathrm{N}_{2}$ flow at a heating rate of $10^{\circ} \mathrm{C} / \mathrm{min}$ from room temperature (RT) to $700^{\circ} \mathrm{C}$ with a DuPont Instruments 951 Thermogravimetric Analyzer.

\subsubsection{Water content}

The water content of the condensables $(5-10 \mathrm{~mL})$ is measured using the Dean-Stark method.

\subsubsection{Calorimetry}

The bio-oil samples and/or crystals (approximately $1 \mathrm{~g}$ ) are analysed with an IKA C5003 control calorimeter equipped with an IKA KV 600 Digital water cooler and a Sartorius CP224S analytical balance. Oxygen is connected to the system to pressurise the bomb. Measurements are executed in dynamic mode and the calibration of the system is performed with benzoic acid.

However, the calorific value of the input materials is determined with the aid of Equation 1 . In 2002, presented a 'unified correlation' based on the ultimate analysis for estimating the higher heating value (H.H.V.) of solid, liquid and gaseous fuels on a dry basis:

$$
H H V=0.3491 \mathrm{C}+1.1783 \mathrm{H}+0.1005 S-0.1034 O-0.0151 \mathrm{~N}-0.0211 \mathrm{~A}(\mathrm{MJ} / \mathrm{kg})(1)
$$

$\mathrm{C}, \mathrm{H}, \mathrm{O}, \mathrm{N}, \mathrm{S}$ and $\mathrm{A}$ respectively represent the carbon, hydrogen, oxygen, nitrogen, sulphur and ash content of the material, expressed in mass percentages on a dry basis. This correlation offers predictions with an average absolute error of $1.45 \%$ [16].

\section{RESULTS AND DISCUSSION}

The main characteristics of the biomass and the biopolymers are listed in Table 1. All materials have a high $\mathrm{C}$ - and $\mathrm{O}$-content, an intermediate $\mathrm{H}$-content, and a very low to negligible $\mathrm{N}$-content. No $\mathrm{S}$ is detected. The calorific value of the input materials is calculated with a unified correlation based on their ultimate analysis [16]. TGA is executed to obtain an overview of the basic characteristics. 
Table 1. Main characteristics (on dry basis) of willow and the biopolymers.

\begin{tabular}{|c|c|c|c|c|c|c|c|c|}
\hline Characteristics & Willow & PLA & Corn starch & PHB & Biopearls & Eastar & Solanyl & $\begin{array}{l}\text { Potato } \\
\text { starch }\end{array}$ \\
\hline \multicolumn{9}{|l|}{$\begin{array}{l}\text { Proximate analysis } \\
(\%)\end{array}$} \\
\hline Moisture & 1.88 & 0.00 & 0.48 & 0.17 & 0.00 & 0.00 & 1.05 & 0.00 \\
\hline Volatile & 75.27 & 98.05 & 92.78 & 97.97 & 94.92 & 95.02 & 80.81 & 87.56 \\
\hline Fixed C & 21.14 & 1.30 & 4.62 & 0.80 & 1.77 & 3.68 & 13.00 & 3.87 \\
\hline Ash & 1.71 & 0.65 & 2.12 & 1.06 & 3.31 & 1.30 & 5.14 & 8.57 \\
\hline \multicolumn{9}{|l|}{$\begin{array}{l}\text { Ultimate analysis } \\
(\%)\end{array}$} \\
\hline Carbon & 46.91 & 49.84 & 56.21 & 55.96 & 52.85 & 62.45 & 43.96 & 49.76 \\
\hline Hydrogen & 5.95 & 5.63 & 6.89 & 7.07 & 6.01 & 7.07 & 7.21 & 5.65 \\
\hline Nitrogen & 0.63 & 0.15 & 0.18 & 0.14 & 0.00 & 0.03 & 0.10 & 0.10 \\
\hline Oxygen & 41.69 & 44.42 & 36.77 & 36.40 & 33.15 & 31.85 & 50.00 & 39.33 \\
\hline $\mathrm{H} / \mathrm{C}$ molar ratio & 1.52 & 1.36 & 1.47 & 1.52 & 1.36 & 1.36 & 1.97 & 1.36 \\
\hline $\mathrm{O} / \mathrm{C}$ molar ratio & 0.67 & 0.67 & 0.49 & 0.49 & 0.47 & 0.38 & 0.85 & 0.59 \\
\hline \multicolumn{9}{|l|}{ Calorific value (J/g) } \\
\hline Unified correlation & 19088 & 19424 & 23892 & 24078 & 22034 & 26811 & 18562 & 19780 \\
\hline
\end{tabular}


Kalmar ECO-TECH '07

KALMAR, SWEDEN, November 26-28, 2007

Table 2. The overall score and ranking of the different biopolymer options.

\begin{tabular}{cll}
\hline Ranking & Biopolymer option & Score \\
\hline 1 & Willow/PHB & 0.346 \\
\hline 2 & Willow/PLA & 0.137 \\
\hline 3 & Willow/Biopearls & 0.128 \\
\hline 4 & Willow/Potato starch & 0.127 \\
\hline 5 & Willow/Solanyl & 0.101 \\
\hline 6 & Willow/Eastar & 0.076 \\
\hline 7 & Willow & 0.044 \\
\hline 8 & Willow/Corn starch & 0.042 \\
\hline
\end{tabular}

To evaluate the effect of the different biopolymers on the pyrolysis behaviour of willow, the flash co-pyrolysis of each biopolymer option (pure willow, and 1:1 willow/biopolymer blends) is performed at $4508 \mathrm{C}$ using the semi-continuous home-built pyrolysis reactor. There is not a single biopolymer option that excels in all areas of interest. Additionally, not all areas of interest are equally important. This makes deciding which biopolymer option is the best one to pursue a subjective decision, even though it should depend on the goal of the pyrolysis and on the latest economical factors.

In order to determine which biopolymer(s) is (are) the most performant to co-pyrolyse with willow, Thomas Saaty's Analytic Hierarchy Process (AHP) is performed on the pyrolysis data [15]. AHP provides a powerful tool that can be used to make straightforward decisions in situations involving multiple objectives. In a first attempt, nine objectives are selected in order to evaluate the different biopolymer options: bio-oil yield, total amount of gases, total amount of char, total amount of condensables, total amount of readily separable chemicals, total amount of pyrolytic water, water content, water-free bio-oil yield and energy recuperation. With the aid of matrix calculations, an overall score for each biopolymer option is calculated and can easily be converted in a ranking (Table 2). From this, it can be concluded that PHB is the best biopolymer option to pursue, followed by PLA, Biopearls and Potato starch. In general, it can also be concluded that, besides Corn starch, all other biopolymer options result in a more performant pyrolysis process as compared to pure willow. In order to make the evaluation process unambiguous, further research is still required.

\section{CONCLUSIONS}

The flash co-pyrolysis of biomass and biopolymers is a promising route and can be considered a win-win situation, which can easily be converted into an economically attractive industrial process. Besides an alternative waste treatment option, it also serves as a supplier of value-added materials and renewable energy. Even though all 1:1 willow/biopolymers blends, except 1:1 willow/Corn starch, resulted in improved pyrolysis characteristics at $4508 \mathrm{C}$ as compared to pure willow, polyhydroxybutyrate (PHB), polylactic acid (PLA), Biopearls, and Potato starch obtained the highest global score for the predefined objectives.

\section{ACKNOWLEDGMENTS}

The authors would like to thank the many suppliers of the biopolymer samples: Biomer, Luts Plastic Production, Rodenburg Biopolymers, Biopearls, and Jemaco. This work fits into an association bursary between Xios and University Hasselt. 


\section{REFERENCES}

[1] European Commission, 2000. Towards a European strategy for the security of energy supply. Green Paper 2000; 1-111.

[2] Demirbas A, Arin G., 2002. An overview of biomass pyrolysis. Energy Sources, 24, 471-82.

[3] Babu, B.V., Chaurasia, A,S., 2003. Modeling, simulation and estimation of optimum parameters in pyrolysis of biomass. Energy Conv. Manag. 44, 2135-58.

[4] Onay, O., Kockar, O.M., 2003. Slow, fast and flash pyrolysis of rapeseed. Renew: Energy, 28, 2417-33.

[5] Czernik, S., Bridgwater, A.V., 2005. Applications of biomass fast pyrolysis oil. In: Bridgwater AV, editor. Fast Pyrolysis of Biomass: A Handbook Volume 3, United Kingdom: CPL Press. 105-20.

[6] Bridgwater, A.V., 2000. Peacocke GVC. Fast pyrolysis processes for biomass. Renew. Sust. Energ. Rev. 4, 1-73.

[7] Doshi, V,A,, Vuthaluru, H,B,, Bastow, T., 2005. Investigations into the control of odour and viscosity of biomass oil derived from pyrolysis of sewage sludge. Fuel Process. Technol. 86, 885-97.

[8] Mohan, D., Pittman, C.U., 2006. Steele PH. Pyrolysis of wood/biomass for bio-oil: A critical review. Energy Fuels, 20, 848-89.

[9] McNeill, I.C., Leiper, H.A., 1985. Degradation studies of some polyesters and polycarbonates. 2. Polylactide - Degradation under Isothermal Conditions, ThermalDegradation Mechanism and Photolysis of the Polymer. Polym. Degrad. Stabil, 11, 309-26.

[10] Kopinke, F,D,, Remmler, M,, Mackenzie, K,, Moder, M., Wachsen, O., 1996. Thermal decomposition of biodegradable polyesters .2. Poly(lactic acid). Polym. Degrad. Stabil. 53, 329-42.

[11] Kopinke, F,D,, Mackenzie, K., 1997. Mechanistic aspects of the thermal degradation of poly(lactic acid) and poly(beta-hydroxybutyric acid). J. Anal. Appl. Pyrolysis. 40-1, 43-53.

[12] Westphal, C., Perrot, C., Karlsson, S., 2001. Py-GC/MS as a means to predict degree of degradation by giving microstructural changes modelled on LDPE and PLA. Polym. Degrad. Stabil. 73, $281-7$.

[13] Kopinke, F,D,, Remmler, M,, Mackenzie, K., 1996. Thermal decomposition of biodegradable polyesters .1. Poly(beta-hydroxybutyric acid). Polym. Degrad. Stabil. 52, 25-38.

[14] Cornelissen, T,, Yperman, J., Reggers, G., Schreurs, S., Carleer, R. Flash co-pyrolysis of biomass with polylactic acid. Part 1: Influence on bio-oil yield and heating value. In Press, Corrected Proof.

[15] Winston, W.L., 1994. Operations research - applications and algorithms (Handbook), Third edition, 771-823.

[16] Channiwala, S.A., Parikh, P.P., 2002. A unified correlation for estimating HHV of solid, liquid and gaseous fuels. Fuel, 81, 1051-63. 